\title{
Validation of IIR/CALIPSO Level 1 Measurements by Comparison with Collocated Airborne Observations during CIRCLE-2 and Biscay '08 Campaigns
}

\author{
ODRAN SOURDEVAL AND GÉRARD BROGNIEZ \\ Laboratoire d'Optique Atmosphérique, Université de Lille 1, Sciences et Technologies, Villeneuve d'Ascq, France \\ JACQUES PELON \\ Laboratoire Atmosphères, Milieux, Observations Spatiales, Université Pierre et Marie Curie, Paris, France \\ LAurent C.-LABonnote, PhilipPe Dubuisson, AND FrédÉRIC PAROL \\ Laboratoire d'Optique Atmosphérique, Université de Lille 1, Sciences et Technologies, Villeneuve d'Ascq, France \\ DAmien Josset, ANne GARnier, AND Michä̈l FAIVRe \\ Laboratoire Atmosphères, Milieux, Observations Spatiales, Université Pierre et Marie Curie, Paris, France
}

ANDREAS MINIKIN

Deutsches Zentrum für Luft- und Raumfahrt (DLR), Institut für Physik der Atmosphäre, Oberpfaffenhofen, Germany

(Manuscript received 14 August 2011, in final form 19 December 2011)

\begin{abstract}
In the frame of validation of the spatial observations from the radiometer IIR on board CALIPSO, the two airborne campaigns Cirrus Cloud Experiment (CIRCLE)-2 and Biscay '08 took place in 2007 and 2008 in the western part of France, over the Atlantic Ocean. During these experiments, remote sensing measurements were made over cirrus clouds, right under the track of Cloud-Aerosol Lidar and Infrared Pathfinder Satellite Observations (CALIPSO) in space and time collocation. For this purpose, a Falcon-20 aircraft was equipped with the Lidar pour l'Etude des Interactions Aérosols Nuages Dynamique Rayonnement et du Cycle de l'Eau (LEANDRE)-New Generation (NG) and the thermal infrared radiometer Conveyable Low-Noise Infrared Radiometer for Measurements of Atmosphere and Ground Surface Targets (CLIMAT)-Airborne Version (AV), whose spectral characteristics are strongly similar to those of the infrared imaging radiometer (IIR). In situ measurements were also taken in cirrus clouds during CIRCLE-2. After comparisons, consistent agreements are found between brightness temperatures measured by CLIMAT-AV and IIR. However, deviations in the brightness temperature measurements are still observed, mainly in the $8.6-\mu \mathrm{m}$ channels. Simulations using a radiative transfer code are performed along a perfectly clear-sky area to show that these dissimilarities are inherent in slight differences between the spectral channels of both radiometers, and in differences between their altitudes. Cloudy and imperfectly clear areas are found to be harder to interpret, but the measurements are still coherent by taking into account experimental uncertainties. In the end, IIR measurements can be validated unambiguously.
\end{abstract}

\section{Introduction}

Cirrus clouds generally occur at altitudes of about $6 \mathrm{~km}$ and permanently cover nearly $30 \%$ of the globe

Corresponding author address: Pr. Gérard Brogniez Laboratoire d'Optique Atmosphérique, Université de Lille 1, Sciences et Technologies, Villeneuve d'Ascq 59650 CEDEX, France.

E-mail: gerard.brogniez@univ-lille1.fr
(Warren et al. 1988). Their impact on the earth radiation budget has been clearly identified as one of the major issues in climate research (Liou 1986). In this regard, improvements in our knowledge of cirrus clouds have been made a primary objective of the World Climate Research Programme (WCP 1986). Reliable model predictions of their impact require an appropriate description of their properties, such as geometrical position, ice crystal shape and size, and vertical distribution of ice water 
content. These conditions are discussed in a review paper by Baran (2009). More particularly, it has been shown that the shape and size distribution of ice crystals to a large extent modify the scattering properties of cirrus clouds (e.g., Takano and Liou 1989; Brogniez et al. 1992; C.-Labonnote et al. 2000, 2001; Baran et al. 2001; Baran and C.-Labonnote 2007; Knapp et al. 1999, 2005; Baum et al. 2005, 2011; Baran 2009) and, consequently, their radiative properties. It is thus essential to carefully constrain these properties, which are still poorly understood, in order to better represent their radiative effects in climate models. The main difficulties in the quantification of cirrus clouds properties are due to several factors, such as their semitransparency, their high altitude, or their large spatial inhomogeneity. Moreover, their microphysics can be described by a large variety of ice crystals with various sizes, shapes, and size distributions, which introduce significant uncertainties regarding their optical properties. These difficulties make observations and studies of cirrus clouds laborious for both aircraft and satellites. Until now, the following several field experiments have been conducted on natural cirrus: the First International Satellite Cloud Climatology Project (ISCCP) Regional Experiment (FIRE; e.g., Paltridge and Platt 1981; Ackerman et al. 1990), International Cirrus Experiment (ICE; Raschke et al. 1990); European Cloud Radiation Experiment (EUCREX; Sauvage et al. 1999; Chepfer et al. 1999), Field Radiation Experiment on Natural Cirrus and High-Level Clouds (FRENCH; Brogniez et al. 2004), Cirrus Regional Study of Tropical Anvils and Cirrus Layers-Florida-Area Cirrus Experiment (CRYSTAL-FACE; e.g., Garrett et al. 2005), Aerosol and Chemical Transport in Tropical Convection (ACTIVE; e.g., Vaughan et al. 2005), and Tropical Composition, Cloud and Climate Coupling ( $\mathrm{TC}^{4}$; e.g., King et al. 2010), among others. These airborne experiments combined in situ and radiative measurements, which notably led to a much better understanding of cirrus clouds' microphysical structure. However, in the prospective of global-scale studies, the use of remote sensing techniques from satellites appears necessary. Nowadays, thanks to the A-Train satellite constellation, more synergies have become possible between various instruments for a better understanding of the atmosphere, particularly in the case of cirrus cloud study (e.g., Delanoë and Hogan 2010). It is not only important for climate model evaluation, but also for forward radiative transfer calculations, which means that the radiative transfer modeling must be physically consistent across the electromagnetic spectrum. This aspect is particularly discussed by Baran (2009). In this prospect, the use of Cloud-Aerosol Lidar and Infrared Pathfinder Satellite Observations (CALIPSO), which carries the Cloud-Aerosol Lidar with Orthogonal
Polarization (CALIOP) and the infrared imaging radiometer (IIR), is of great interest to the research on cirrus clouds. Indeed, it has already been shown that infrared measurements are very efficient for retrieval of ice clouds properties, such as optical thickness, cloud-top pressure, and even microphysical properties (e.g., Parol et al. 1991). To use these measurements to retrieve such properties, an essential step is to validate them through airborne field experiments. It is in this frame that the two airborne campaigns Cirrus Cloud Experiment (CIRCLE)-2 and "Biscay '08" were conducted between 2007 and 2008 over the Atlantic Ocean, off the Brittany coast and Biscay Bay. In this respect, the present paper will focus on the level-1 validation (radiances/brightness temperatures) of the satellite measurements. More particularly, we have studied and compared the measurements of infrared upward radiances obtained from the satellite with those of a collocated aircraft over various clear-sky and cirrus cloud scenes and have analyzed the consistency of these observations using a radiative transfer model.

\section{The A-Train constellation}

The constellation of satellites called A-Train consists of several satellites flying in close proximity. These satellites cross the equator within a few minutes of one another at around 1330 local time (LT). The constellation has a nominal orbital altitude of $705 \mathrm{~km}$ and an inclination of $98^{\circ}$. The satellites within the A-Train constellation have highly complementary measurement capabilities and are sufficiently close to one another to observe the same target within a brief time interval. For the first time, nearly simultaneous measurements of aerosols, clouds, temperature, relative humidity, and radiative fluxes are obtained over the globe during all seasons. This set of observations will allow us to understand how large-scale aerosol and cloud properties change under various environmental conditions (Anderson et al. 2005). The first satellite Aqua was launched in May 2002, with the intent to collect new information on the earth's water cycle. Particularly, it carries a Moderate Resolution Imaging Spectroradiometer (MODIS), a spectrometer providing radiances in 36 spectral bands with wavelengths ranging from 0.4 to $14.4 \mu \mathrm{m}$. Aura was launched in July 2004 in order to study atmospheric profiles. In December 2004, Polarisation et Anisotropie des Réflectances au sommet de l'Atmosphère, Couplées avec un Satellite d'Observation Emportant un Lidar (PARASOL) joined the A-Train to provide new information on clouds and aerosols thanks to its unique ability to measure polarized and multidirectional reflectances in nine spectral channels from 0.443 to $1.02 \mu \mathrm{m}$. Three of the channels $(0.49,0.67$, and $0.865 \mu \mathrm{m})$ have polarization capabilities. 


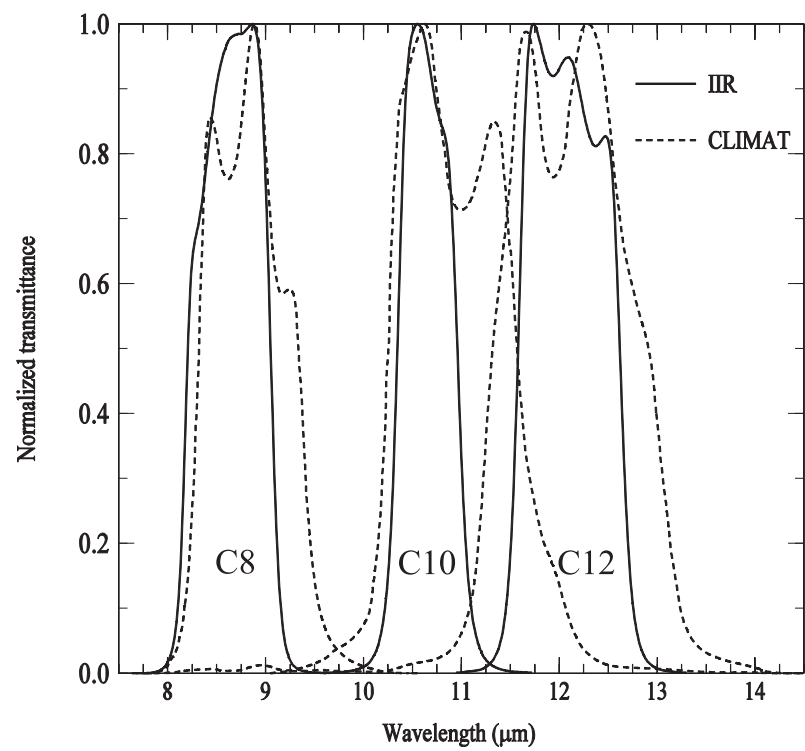

FIG. 1. Normalized spectral band transmissions in channels C8, C10, and C12 of CLIMAT-AV and IIR.

Finally, in April 2006, CloudSat and CALIPSO were launched to provide more information on clouds and aerosols, specifically using the $94-\mathrm{GHz}$ cloud profiler radar (CPR), 532- and 1064-nm CALIOP, and IIR. IIR and CALIOP on board CALIPSO provide a unique opportunity of synergy in the case of cirrus clouds studies. The radiometer IIR measures emitted radiances in three bands $-8.65,10.60$, and $12.05 \mu \mathrm{m}-$ at about $1-\mu \mathrm{m}$ full

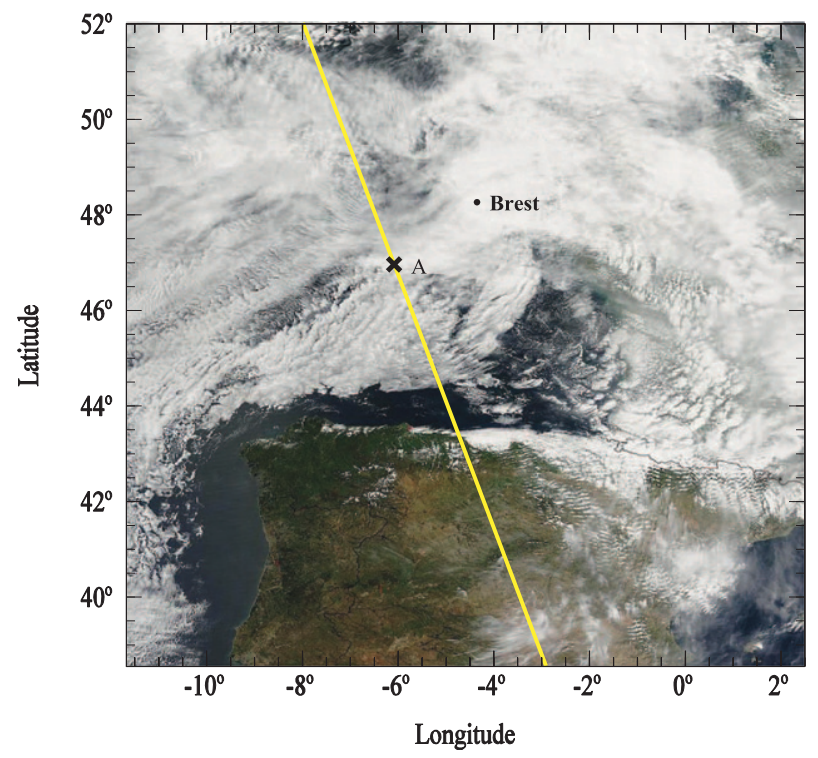

FIG. 2. Cloud field observed by MODIS at 1333 UTC 16 May 2007, off the Brittany coast, during CIRCLE-2. The CALIPSO track (yellow thick line) is superimposed. The starting point A of the first FF20 leg of flight fs0708 is toward the north.

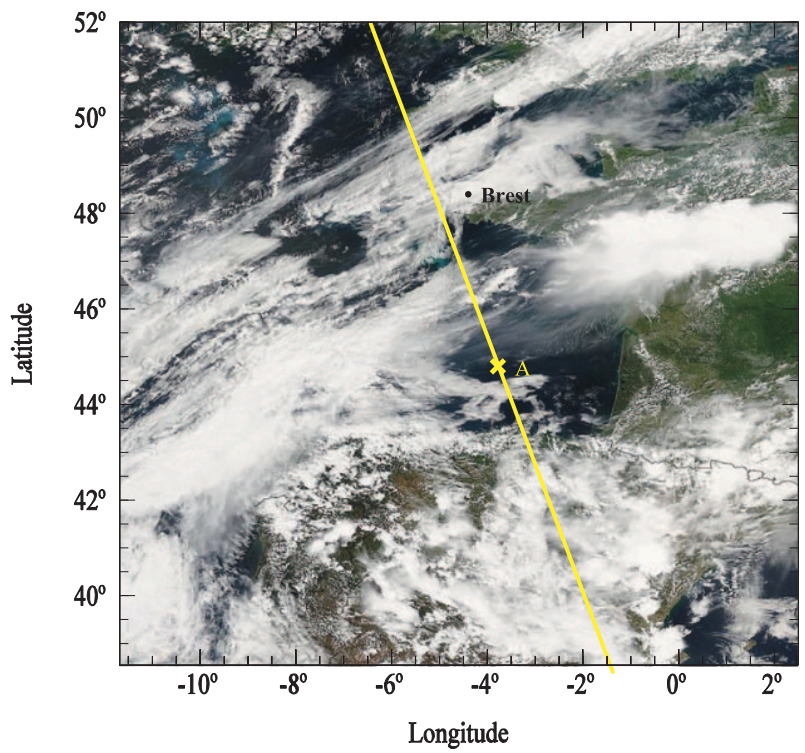

FIG. 3. Cloud field observed by MODIS at 1327 UTC 25 May 2007 off the Brittany coast, during CIRCLE-2. The CALIPSO track (yellow thick line) is superimposed. The starting point A of the first FF20 leg of flight fs 0713 is toward the north.

width at half maximum (FWHM), with a swath of about $64 \mathrm{~km}$ and a pixel size of $1 \mathrm{~km}$. The brightness temperature precision is better than $0.3 \mathrm{~K}$ for a source at $250 \mathrm{~K}$, whereas its absolute accuracy is considered to be better than $1 \mathrm{~K}$ at $210 \mathrm{~K}$ (Corlay et al. 2000).

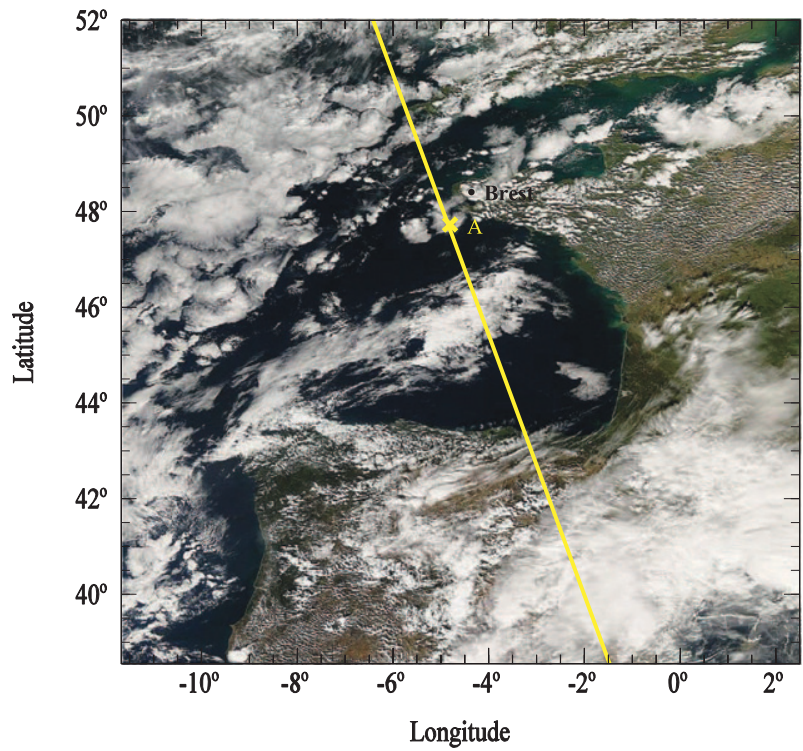

FIG. 4. Cloud field observed by MODIS at 1333 UTC 18 Oct 2007 off the Brittany coast and Biscay Bay, during the Biscay '08 experiment. The CALIPSO track (yellow thick line) is superimposed. The starting point A of the FF20 leg of flight fs 0818 is toward the south. 
TABLE 1. Summary of mission case studies conducted over the ocean during CIRCLE-2 and Biscay '08 in collocation with FF20, GF20, and CALIPSO overpasses.

\begin{tabular}{lccccc}
\hline \hline Campaign & Day & $\begin{array}{c}\text { FF20 } \\
\text { flight name }\end{array}$ & $\begin{array}{c}\text { Measurement period: } \\
\text { Start-end (UTC) }\end{array}$ & Flight operation & Cloud type \\
\hline CIRCLE-2 (2007) & 16 May & fs0708 & $1220: 00-1530: 00$ & Brest-Brest & $\begin{array}{c}\text { Frontal cirrus and low } \\
\text { clouds (northwest low) } \\
\text { Fiscay '08 }\end{array}$ \\
25 May & fs0713 & $1120: 00-1500: 00$ & Brest-Brest & $\begin{array}{c}\text { Frontal cirrus } \\
\text { (northwest low) }\end{array}$ \\
18 Oct & fs0818 & $1215: 00-1540: 00$ & $\begin{array}{c}\text { Creil-Biscay - } \\
\text { Thick frontal cirrus } \\
\text { (southeast low) }\end{array}$ \\
\hline
\end{tabular}

\section{CALIPSO-collocated airborne experiments}

\section{a. The airborne campaigns CIRCLE-2 and Biscay '08}

Two airborne campaigns with the aim of validating IIR measurements were conducted: the Franco-German CIRCLE-2, from 12 to 26 May 2007, and the French Biscay '08 campaign, from 2 September to 18 October 2008. These campaigns took place in the western part of France over the Atlantic Ocean, off the Brittany coast and Biscay Bay.

The Biscay ' 08 and CIRCLE-2 campaigns both involved the French Falcon-20 (FF20) operated by the Service des Avions Français Instrumentés pour la Recherche en Environnement (SAFIRE) from Creil, near Paris, France. This aircraft carried active and passive remote sensing instrumentation. It flew at its maximum ceiling, that is, at an altitude of about $12000 \mathrm{~m}$, under the track of CALIPSO.

In addition to the FF20 aircraft, the CIRCLE-2 campaign also involved the German Falcon-20 (GF20) operated by the Deutsches Zentrum für Luft- und Raumfahrt (DLR), from Oberpfaffenhofen, near Munich, Germany. This aircraft was designed to provide in situ measurements of cloud microphysical and optical properties thanks to a Particle Measuring System (PMS) Forward Scattering Spectrometer Probe (FSSP)-300, a PMS two-dimensional cloud probe (2D-C), a polar nephelometer probe (Gayet et al. 1998), and a cloud particle imager (CPI; Lawson et al. 2001). In this regard, the GF20 legs were performed at different levels from cloud top to base. Both aircraft had identical performances, and their altitudes and positions were given by their GPS systems with an accuracy of $20 \mathrm{~m}$ in order to accurately follow the track of CALIPSO.

\section{b. Instrumentation on board FF20 aircraft during the two campaigns}

During the CIRCLE-2 and Biscay '08 campaigns, the FF20 aircraft was equipped with two nadir-viewing instruments:

1) The Lidar pour l'Etude des Interactions Aérosols Nuages Dynamique Rayonnement et du Cycle de
l'Eau (LEANDRE)-New Generation (LNG) works in a backscatter mode at three wavelengths: $355 \mathrm{~nm}$ with linear depolarization capability, $532 \mathrm{~nm}$, and $1064 \mathrm{~nm}$ (these last two are the same as those of CALIOP). The LNG's laser beam divergence of 2.5 $\mathrm{mrad}$ at $532 \mathrm{~nm}$ gives a footprint of $2.5 \mathrm{~m}$ at a $1-\mathrm{km}$ range. The backscattered signal is collected using a receiver telescope (30-cm diameter, 5-mrad field of view). The ultimate vertical resolution along the line of sight is $75 \mathrm{~m}$. The backscatter lidar LNG provides direct information on cirrus cloud structure (height and geometrical thickness), optical properties (profiles of volume extinction and volume backscatter coefficients), and parameters linked to the microphysical characteristics of cloud particles (backscatter-toextinction lidar ratio and depolarization ratio).

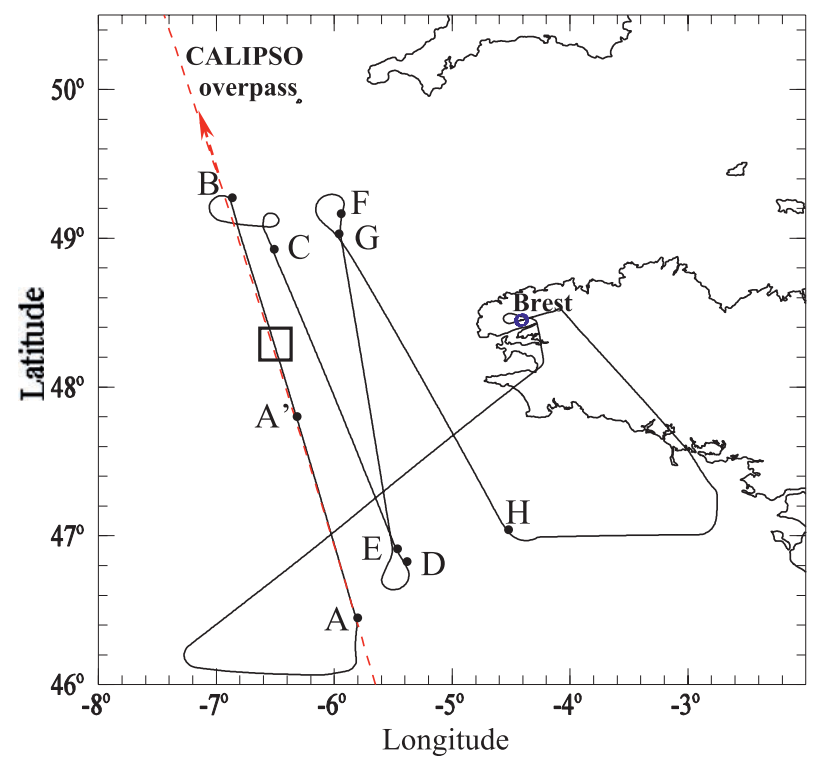

FIG. 5. Flight tracks of FF20 on 16 May 2007 (flight fs0708 during CIRCLE-2) from point A to point H. CLIMAT-AV data are only available from $\mathrm{A}^{\prime}$. The CALIPSO overpass is superimposed (red dashed line). The exact time and position of the collocation between CALIPSO and FF20 is performed during leg $\mathrm{A}^{\prime} \mathrm{B}$ (square box; see Table 2). 


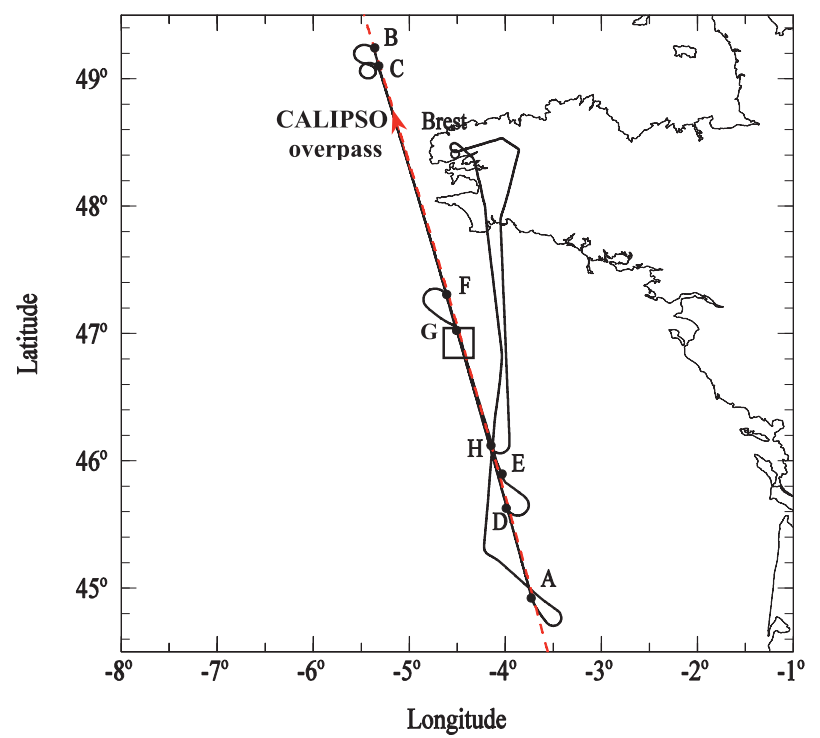

FIG. 6. Flight tracks of FF20 on 25 May 2007 (flight fs0713 during CIRCLE-2) from point A to point $\mathrm{H}$. The CALIPSO overpass is superimposed (red dashed line). The exact time and position of the collocation between CALIPSO and FF20 was made during the return leg CD (square box; see Table 2).

2) The aircraft was also equipped with the thermal infrared radiometer Conveyable Low-Noise Infrared Radiometer for Measurements of Atmosphere and Ground Surface Targets (CLIMAT)-Airborne Version (AV) (Legrand et al. 2000; Brogniez et al. 2003; Brogniez et al. 2005). It uses a 7-Hz sampling frequency and performs measurements within a 50-mrad field of view, which corresponds to a footprint of about $50 \mathrm{~m}$ at a 1-km range. Radiances are measured simultaneously in three narrowband channels centered at 8.7 (C8), 10.8 (C10), and 12.0 (C12) $\mu \mathrm{m}$, with about $1 \mu \mathrm{m}$ of FWHM. Spectral bandpasses of CLIMAT-AV and IIR are presented in Fig. 1. They are fairly close to each other, yet present some differences in spectral features that will require further analysis in order to properly compare measured brightness temperatures. The absolute accuracy of brightness temperature measurements derived from CLIMAT-AV is about of $0.1 \mathrm{~K}$, whereas their sensitivity is of the order of $0.05 \mathrm{~K}$ (Brogniez et al. 2003).

\section{c. Summary and description of the selected cases scenes during CIRCLE-2 and Biscay '08}

To validate the IIR on board CALIPSO, its brightness temperature measurements are compared with those of CLIMAT-AV along collocated tracks. As a consequence, only the following flights that are well collocated with CALIPSO are analyzed here.

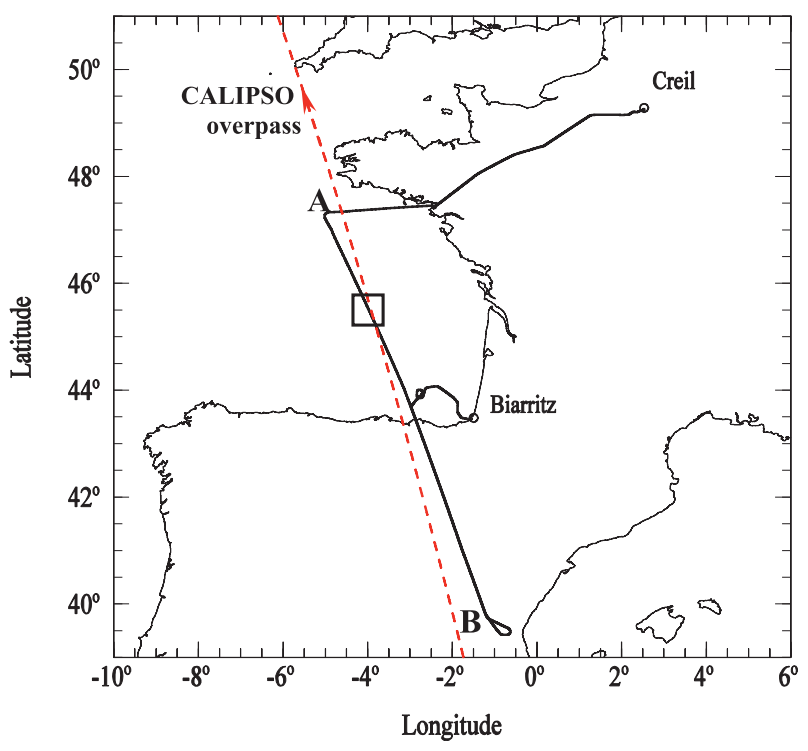

FIG. 7. Flight tracks of FF20 on 18 Oct 2008 (flight fs0818 during Biscay '08) from A to B. The ascending CALIPSO overpass is superimposed (red dashed line). The exact time and position of the collocation between CALIPSO and FF20 is represented (square box; see Table 2).

- During CIRCLE-2, only 16 and 25 May are considered significant for the validation of IIR. Additionally, both FF20 and GF20 aircrafts were perfectly operational and in great coordination, as pointed out by Mioche et al. (2011). Wide-scale overviews of the atmospheric conditions using MODIS "RGB true color" (Figs. 2 and 3 ) show thin frontal cirrus clouds present all over the Atlantic Ocean during these 2 days.

- During Biscay ' 08 , only 18 October is exploitable for IIR validation. However, this day is particularly interesting because it featured very thick cirrus decks situated over the northeastern Spain and also a very noticeable clear-sky area over Biscay Bay (Fig. 4).

A summary of the case study missions is presented in Table 1.

\section{d. Description of FF20 flight plans during CIRCLE-2 and Biscay' 08}

The FF20 track performed during the flight fs 0708 on 16 May 2007 is presented in Fig. 5, where the leg AB is coincident with the track of CALIPSO. The total time spent by FF20 to perform this leg was $30 \mathrm{~min}, 35 \mathrm{~s}$ versus $49 \mathrm{~s}$ for CALIPSO. The return leg CD is carried out following a Lagrangian trajectory in order to come across the same cloud structures as in leg AB.

Figure 6 presents the FF20 track performed during the flight fs0713 on 25 May 2007. All of the legs (AB, CD, 
TABLE 2. Summary of some schedules characteristics for the flights fs 0708 , fs 0713 , and fs 0818 during CIRCLE-2 and Biscay '08 campaigns.

\begin{tabular}{|c|c|c|c|}
\hline FF20 flights & $\begin{array}{c}\text { Legs FF20 } \\
(\text { start } \rightarrow \text { end time UTC) }\end{array}$ & Mean altitude & CALIPSO overpass \\
\hline \multirow[t]{5}{*}{ CIRCLE-2 (fs0708) } & A $(1313: 16) \rightarrow B(1343: 51)$ & \multirow[t]{5}{*}{$12600 \mathrm{~m}$} & During leg $\mathrm{AB}$ \\
\hline & $\mathrm{A}^{\prime}(1329: 08 ;$ see Fig. 2$)$ & & A $(1333: 07) \rightarrow$ B $(1333: 56)$ \\
\hline & $\mathrm{C}(1354: 36) \rightarrow \mathrm{D}(1411: 06)$ & & Exact collocation: \\
\hline & $\mathrm{E}(1416: 05) \rightarrow \mathrm{F}(1437: 26)$ & & Time: 1333:38 UTC \\
\hline & $\mathrm{G}(1442: 42) \rightarrow \mathrm{H}(1500: 00)$ & & Latitude: $48.32^{\circ} \mathrm{N}$ \\
\hline \multirow[t]{5}{*}{ CIRCLE-2 (fs0713) } & $\mathrm{A}(1231: 30) \rightarrow \mathrm{B}(1257: 20)$ & \multirow[t]{5}{*}{$12050 \mathrm{~m}$} & During leg CD \\
\hline & $\mathrm{C}(1306: 10) \rightarrow \mathrm{D}(1339: 25)$ & & $\mathrm{D}(1326: 48) \rightarrow \mathrm{C}(1327: 45)$ \\
\hline & $\mathrm{E}(1345: 07) \rightarrow \mathrm{F}(1356: 35)$ & & Exact collocation: \\
\hline & $\mathrm{G}(1403: 20) \rightarrow \mathrm{H}(1409: 40)$ & & Time: 1327:11 UTC \\
\hline & & & Latitude: $46.97^{\circ} \mathrm{N}$ \\
\hline \multirow[t]{5}{*}{ Biscay ‘08 (fs0818) } & A $(1312: 18) \rightarrow$ B $(1426: 06)$ & \multirow[t]{5}{*}{$12400 \mathrm{~m}$} & During leg $\mathrm{AB}$ \\
\hline & & & B $(1326: 48) \rightarrow$ A $(1328: 56)$ \\
\hline & & & Exact collocation: \\
\hline & & & Time: 1328:30 UTC \\
\hline & & & Latitude: $45.65^{\circ} \mathrm{N}$ \\
\hline
\end{tabular}

$\mathrm{EF}$, and $\mathrm{GH}$ ) are well superimposed on the track of CALIPSO. The exact collocation was reached during the return leg $\mathrm{CD}$. The total time spent to perform this leg was $33 \mathrm{~min}, 15 \mathrm{~s}$ for the FF20 versus $57 \mathrm{~s}$ for CALIPSO.

The FF20 track carried out during flight fs0818 on 18 October 2008 for the Biscay ' 08 experiment is presented in Fig. 7. The leg AB was performed southward, in the opposite direction of CALIPSO. The FF20 took $1 \mathrm{~h}, 13 \mathrm{~min}, 48 \mathrm{~s}$ to cover this leg, while CALIPSO took 2 min, $8 \mathrm{~s}$. The tracks of FF20 and CALIPSO are not exactly superimposed because the leg followed a pseudoLagrangian trajectory in order to come across the same cloud structures as that observed by CALIPSO.

In Table 2, a summary of some leg durations in the course of these flights is presented, as well as duration characteristics of the CALIPSO overpass. Features of exact collocations with CALIPSO are also exposed in the table.

\section{Studies of IIR/CALIPSO validation}

In the following section, direct comparisons of CLIMAT-AV and IIR brightness temperature measurements simultaneously obtained over the same track are presented. However, in order to correctly compare these measurements, several considerations have to be taken into account:

1) The resolution of IIR measurements is about $1000 \mathrm{~m}$ at cirrus cloud level, against a maximum of about $50 \mathrm{~m}$ for CLIMAT-AV if the aircraft is situated at a top altitude of $1 \mathrm{~km}$ above cirrus clouds. Considering a 7-Hz sampling frequency for CLIMAT-AV and the speed of the aircraft to be of approximately $120 \mathrm{~m} \mathrm{~s}^{-1}$, each of its measurement data is acquired every $18 \mathrm{~m}$ along the track of the aircraft. Thus, we have effectuated a sliding average of 60 data points of CLIMAT-AV in order for it to correspond to the size of IIR pixel along the track of CALIPSO, which allows making measurements from both instruments comparable.

2) During some campaign days, a slight gap between the tracks of the FF20 aircraft and CALIPSO can be observed. An average of several central pixels in the cross track of IIR is then considered in order to perfectly cover aircraft measurements. As a consequence, standard deviations from this average will

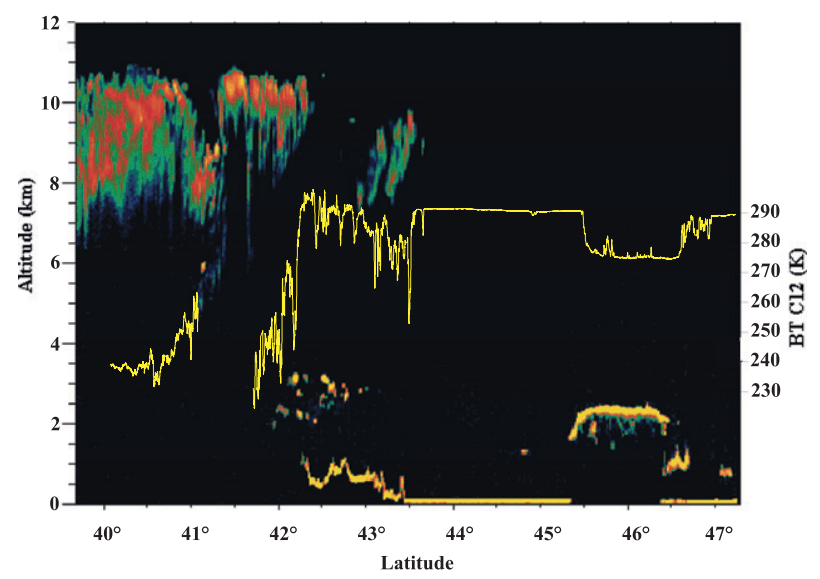

FIG. 8. Composite image obtained from LNG backscattering and CLIMAT-AV brightness temperature in channel C12 (right scale) for the leg $\mathrm{AB}$, performed on 18 Oct 2008 during Biscay ' 08 as represented in Fig. 7. A clear atmosphere is encountered in the latitude range of $43.6^{\circ}-45.2^{\circ} \mathrm{N}$. 

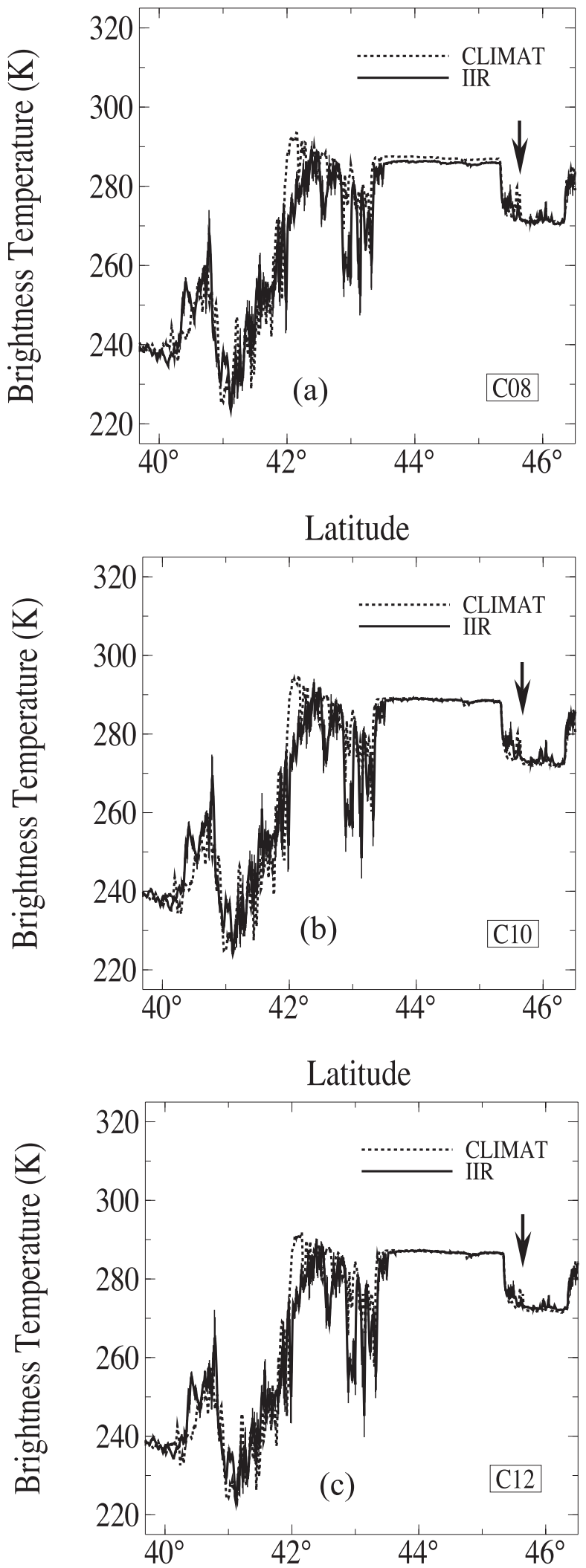

Latitude appear in IIR measurement representations. The exact numbers of central pixels considered for each campaign day are indicated in the following subsections.

3) Because of the overall movement of the cirrus deck, the aircraft and satellite radiometers may not observe the exact same scene. The wind speed at the altitude of the cirrus deck is obtained from radio sounding and from the FF20 aircraft information. By combining this information with the aircraft's and satellite's directions and speeds ( $\sim 120$ and $\sim 7000 \mathrm{~m} \mathrm{~s}^{-1}$, respectively), the latitude shift observed in cloud structures between both instruments is completely compensated, and brightness temperatures versus latitude measurements become comparable. This correction turns out to be particularly efficient close to the collocation point between the FF20 aircraft and CALIPSO. That is why only the measurements made during the leg containing the collocation are used for brightness temperature comparisons.

4) Finally, we are expecting some inherent differences between the brightness temperatures measured by CLIMAT-AV and IIR resulting from two main differences in the observations. First, the two radiometers are not at the same altitude, and thus do not observe the same atmosphere (e.g., the stratospheric ozone layer is viewed by IIR only, which will mostly effect its channel C8). Second, as seen in Fig. 1, the spectral bandwidths of the two instruments are not strictly identical. To interpret the impact of these dissimilarities on brightness temperatures, the Fast Discrete Ordinate Method (FASDOM) radiative code is used (Dubuisson et al. 2005). It provides simulations of upward brightness temperatures in a well-defined atmosphere by taking into account spectral characteristics of the instruments. The spectroscopic database of the radiance code includes High-Resolution Transmission Molecular Absorption Database (HITRAN)-2004 and the continuum parameterization for the water vapor absorption with the $\mathrm{CKD}_{2.4}$ water vapor model (Clough et al. 1989; Tobin et al. 1999; Giver et al. 2000; Rothman et al. 2001). Compared to a line-by-line model, the accuracy of such simulation is considered to be better than $0.3 \mathrm{~K}$ for clear and cloudy atmosphere (Dubuisson et al.

FIG. 9. Brightness temperatures measured for the leg $\mathrm{AB}$ on 18 Oct 2008, during Biscay ' 08 by CLIMAT-AV and IIR in the three common channels $\mathrm{C} 8, \mathrm{C} 10$, and $\mathrm{C} 12$. The exact collocation between FF20 and CALIPSO are indicated (arrows). 
TABLE 3. Simulations of brightness temperature as measured by CLIMAT-AV and IIR in the three common channels (C8, C10, and $\mathrm{C} 12$ ) corresponding to the cloudless area, that is, for the latitude $44.3^{\circ} \mathrm{N}$ during Biscay ' 08 . To evaluate impact of the difference of altitude and spectral bandpasses between the two instruments, simulations are also performed for $\mathrm{IIR}_{13}$ and CLIMAT TOA. $_{\text {. }}$.

\begin{tabular}{|c|c|c|c|c|}
\hline & Instrument location & $\mathrm{C} 8(\mathrm{~K})$ & $\mathrm{C} 10(\mathrm{~K})$ & $\mathrm{C} 12(\mathrm{~K})$ \\
\hline \multirow{3}{*}{$\begin{array}{c}\text { Nominal location } \\
\text { of instruments }\end{array}$} & IIR & 286.51 & 288.81 & 287.03 \\
\hline & CLIMAT & 287.45 & 288.79 & 286.89 \\
\hline & CLIMAT - IIR & 0.94 & -0.02 & -0.14 \\
\hline \multirow{2}{*}{$\begin{array}{l}\text { Supposed location } \\
\text { of instruments }\end{array}$} & $\mathrm{IIR}_{13}$ & 287.05 & 288.96 & 287.12 \\
\hline & CLIMAT $_{\mathrm{TOA}}$ & 286.45 & 288.64 & 286.80 \\
\hline \multirow[t]{2}{*}{ Bandpasses effect } & CLIMAT - IIR 13 & 0.40 & -0.17 & -0.26 \\
\hline & CLIMAT $_{\mathrm{TOA}}-$ IIR & -0.06 & -0.17 & -0.23 \\
\hline \multirow[t]{2}{*}{ Altitude effect } & $\mathrm{IIR}_{13}-\mathrm{IIR}$ & 0.54 & 0.15 & 0.09 \\
\hline & 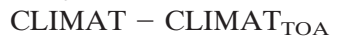 & 1.00 & 0.15 & 0.09 \\
\hline
\end{tabular}

2005). Several specific input parameters are necessary for FASDOM simulations:

(i) The temperature, humidity, and ozone atmospheric profiles are provided by the National Aeronautics and Space Administration's (NASA's) Global Modeling and Assimilation Office (GMAO). They are interpolated along the track of CALIPSO and available in CALIOP operational products for each IIR central pixel.

(ii) The sea surface temperature is provided by European Centre for Medium-Range Weather Forecasts (ECMWF) analyses. Standard ocean emissivity values are used (Wilber et al. 1999). They equal $0.9838,0.9903$, and 0.9857 for channels $\mathrm{C} 8, \mathrm{C} 10$, and $\mathrm{C} 12$, respectively.

The code is set here to simulate an atmosphere of $40-\mathrm{km}$ height divided in layers of $1 \mathrm{~km}$ in clear-sky areas and $100 \mathrm{~m}$ in cloudy areas. Computing brightness temperatures in a cloudy atmosphere implies additional knowledge of clouds microphysical properties. That is why simulations are mostly performed in clear-sky conditions. Cloudy parameters are, however, discussed for CIRCLE-2.

\section{a. Biscay '08 case of 18 October 2008}

On 18 October 2008, the measurement track overlapped by CALIPSO took place between A and B (see Fig. 7) in the latitude range of $40^{\circ}-47^{\circ} \mathrm{N}$. This flight was performed over sea and over land. To precisely represent the atmospheric state during this leg, an image combining LNG backscattering and CLIMAT-AV brightness temperatures in channel $\mathrm{C} 12$ is shown in Fig. 8. This figure confirms the presence of very thick cirrus over Spain (under a latitude of $43.5^{\circ} \mathrm{N}$ ) and a perfectly cloudless area in the latitude range of $43.6^{\circ}-45.2^{\circ} \mathrm{N}$. Only a very thin water cloud can barely be observed around the latitude of $44.8^{\circ} \mathrm{N}$.
Figure 9 shows superposed IIR and CLIMAT-AV brightness temperature measurements for channels $\mathrm{C} 8$, $\mathrm{C} 10$, and $\mathrm{Cl}$. As mentioned previously in this section, several concerns have been taken into consideration for good comparisons of measurements. With the deviation between the satellite's and the aircraft's tracks being large during this campaign day, an average of three of the cross-track central pixels of the IIR swath has been used. Latitude adjustments have also been performed, considering the cirrus deck velocity to be around $25 \mathrm{~m} \mathrm{~s}^{-1}$ toward the northeast. However, by taking a close look at the graphs, some isolated differences can be spotted between CLIMAT-AV and IIR measurements in the three channels above the cloudy atmosphere, particularly in the region situated around $42.2^{\circ} \mathrm{N}$ latitude. In fact, this region is about $34 \mathrm{~min}$ away from the exact collocation indicated by arrows on Fig. 9 for the aircraft, compared with the only $1 \mathrm{~min}$ for CALIPSO. During this time lag, a few cloud features might have changed, explaining these differences. More generally, despite the corrections made on latitudes, it is still hazardous to compare the brightness temperature measurements from both radiometers above cloudy atmosphere too strictly when they are too far from the exact collocation point. Finally, it can still be concluded from Fig. 9 that brightness temperature measurements are in strong overall agreements in every channel.

Nevertheless, expected differences appear between IIR and CLIMAT-AV measurements. A good way to make sure that they come from dissimilarities in the altitude and spectral band passes of the radiometers is to use the FASDOM code for simulations along the clear atmosphere area. Table 3 indicates the informative brightness temperatures measured and simulated for CLIMAT-AV and IIR in the clear atmosphere for each channel at $44.3^{\circ} \mathrm{N}$ latitude. To evaluate the impact of the difference of altitude between the two instruments, as well as the difference of spectral bandpasses, simulations 

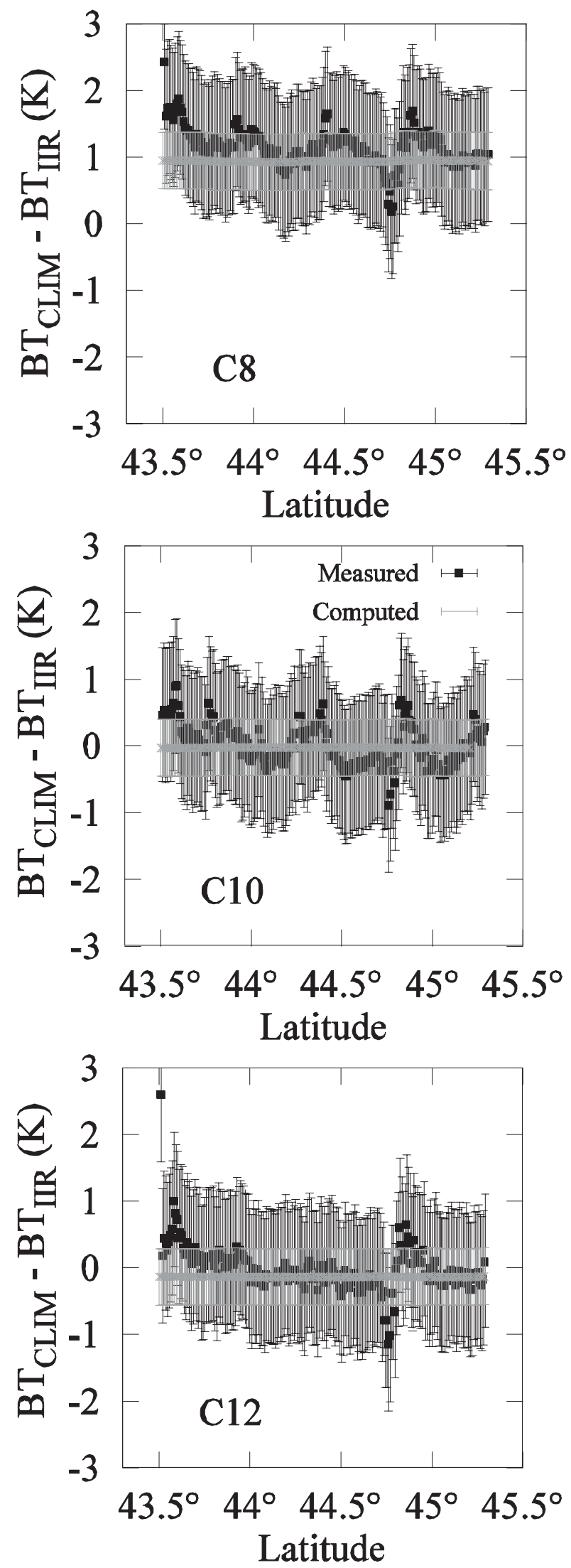

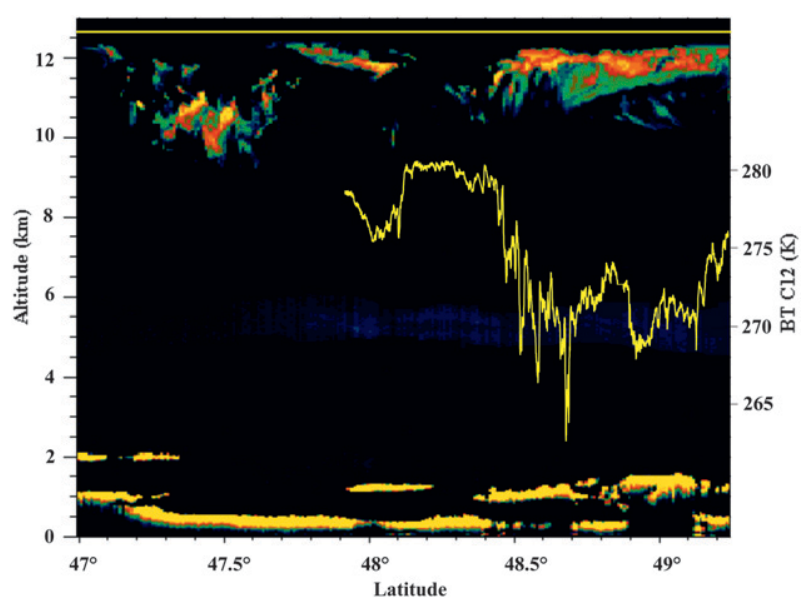

FIG. 11. Composite image obtained from LNG backscattering and CLIMAT-AV brightness temperature in channel C12 (right scale) corresponding to leg AB performed on 16 May 2007 during the CIRCLE-2 experiment, as represented in Fig. 5. The FF20 track at the altitude of $12600 \mathrm{~m}$ is shown (horizontal yellow line).

are also performed for the IIR located at the aircraft's altitude, that is, $13 \mathrm{~km}\left(\mathrm{IIR}_{13}\right)$, and for CLIMAT-AV located at the top of atmosphere (CLIMAT TOA $_{\text {TO }}$. The effect of the spectral channels appears in the brightness temperature differences of CLIMAT - IIR ${ }_{13}$. This difference is negative in channels $\mathrm{C} 10$ and $\mathrm{C} 12$, but is positive

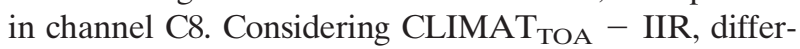
ences remain in the same order as previously in channels $\mathrm{C} 10$ and $\mathrm{C} 12$, but they are now slightly negative in channel C8. This is due to the strong $9.6-\mu \mathrm{m}$ ozone absorption band that is included in channel C8 of CLIMAT-AV, but mostly excluded in channel C8 of IIR (Fig. 1). Similarly, considering IIR $_{13}$ - IIR or CLIMAT - CLIMAT TOA, $_{\text {, }}$ the effect of the atmosphere above $13 \mathrm{~km}$ of altitude is preponderant in channel $\mathrm{C} 8$, again because of the 9.6- $\mu \mathrm{m}$ ozone absorption band. This study shows that the differences of the spectral bands of the instruments, as well as the difference between their locations, are indeed important and could perfectly explain the gap between the measurements of IIR and CLIMAT-AV.

Simulations all along the legs for the latitude range $43.5^{\circ}-45.5^{\circ} \mathrm{N}$, that is, in cloudless area, have then been performed in the same conditions and compared with measurements. The brightness temperature differences

FIG. 10. Brightness temperatures differences in channels C8, $\mathrm{C} 10$, and $\mathrm{C} 12$, obtained from the radiometers CLIMAT-AV and IIR in the latitude range of $43.6^{\circ}-45.2^{\circ} \mathrm{N}$, during Biscay ' 08 . Vertical bars represent uncertainties on simulations and measurements. The legend in the figure $\mathrm{C} 10$ is also valid for the two others. 

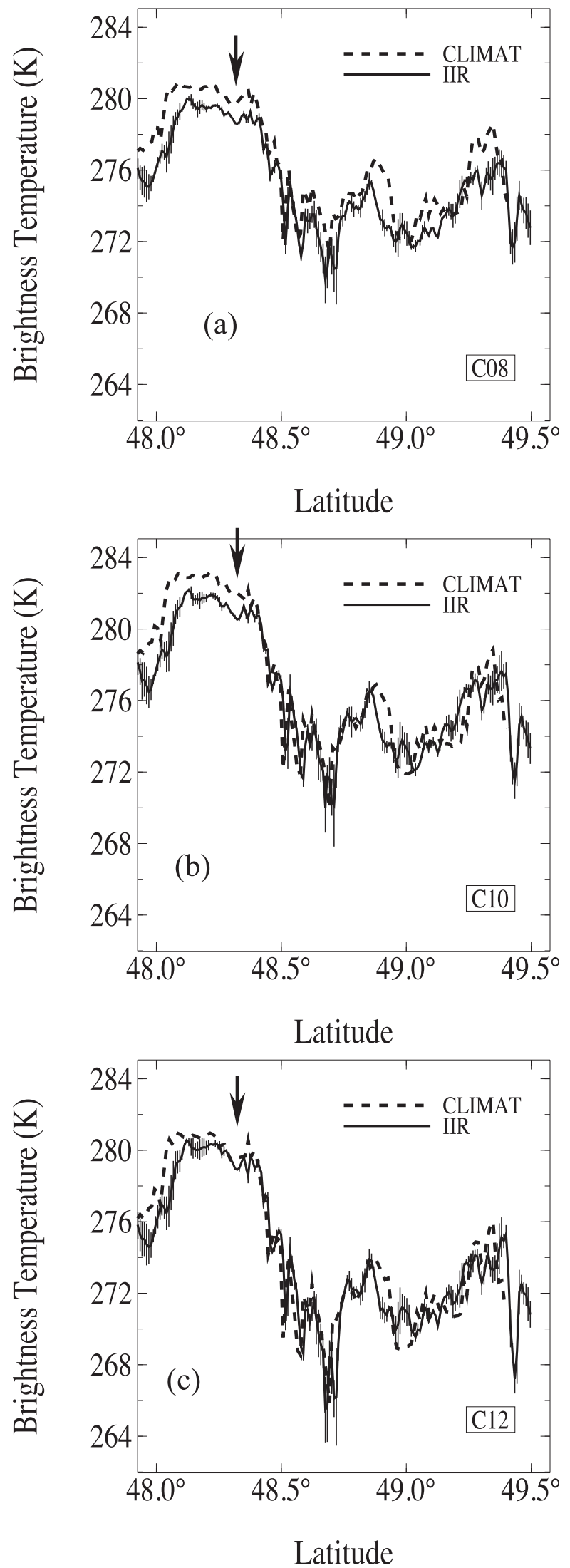

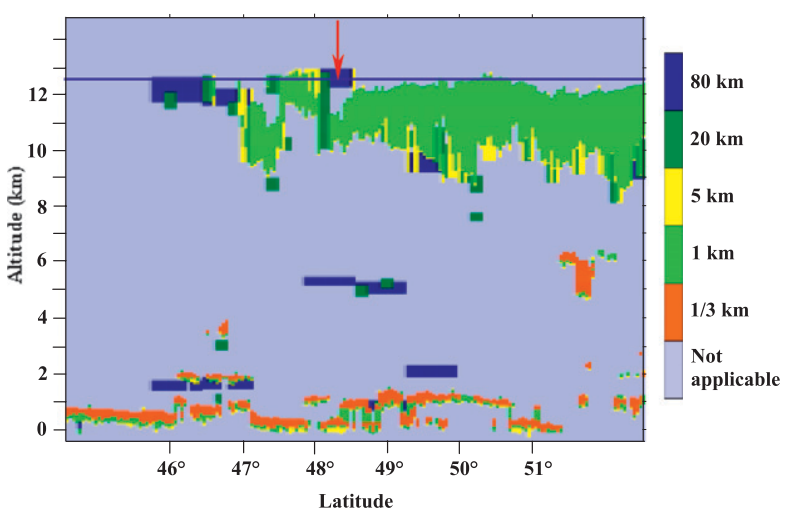

FIG. 13. CALIOP backscattering measurements obtained on 16 May 2007 simultaneously with the track AB of FF20. The FF20 track at the altitude of $12600 \mathrm{~m}$ is shown (horizontal blue line), and the exact collocation between FF20 and CALIPSO is indicated (red vertical arrow). The color scale represents the horizontal resolution with which the structures (clouds, aerosols, and surface) are retrieved layer by layer. For example, the dark blue corresponds to structures found only at $80-\mathrm{km}$ resolution.

between CLIMAT-AV and IIR measurements are shown in Fig. 10. As in Table 3, a difference of about $1 \mathrm{~K}$ is observed for channel C8, whereas no significant differences appear for the other channels. With uncertainties on brightness temperature simulations (BTS) being around $0.3 \mathrm{~K}$, errors deduced from simulations are $\Delta\left(\mathrm{BTS}_{\mathrm{CLIM}}-\mathrm{BTS}_{\mathrm{IIR}}\right) \approx 0.5 \mathrm{~K}$. Similarly, because uncertainties on brightness temperature measurements (BTM) are around 1 and $0.1 \mathrm{~K}$ for IIR and CLIMAT$\mathrm{AV}$, respectively, errors deduced from measurements are $\Delta\left(\mathrm{BTM}_{\text {CLIM }}-\mathrm{BTM}_{\mathrm{IIR}}\right) \gg 1 \mathrm{~K}$. Finally, by taking into account the errors, one can conclude that measurements and simulations are perfectly satisfying in each channel.

\section{b. CIRCLE-2 case of 16 May 2007}

During 16 May 2007, the measurement track overlapped by CALIOP took place between A and B in the latitude range of $47.7^{\circ}-49.4^{\circ} \mathrm{N}$ (see Fig. 5 and Table 2). To characterize the atmospheric state seen by FF20, a composite image combining LNG backscattering and

FIG. 12. Brightness temperature measured during the leg $\mathrm{A}^{\prime} \mathrm{B}$ on 16 May 2007 during CIRCLE-2 by CLIMAT-AV and IIR, in the three common channels $\mathrm{C} 8, \mathrm{C} 10$, and $\mathrm{C} 12$. The exact collocation between FF20 and CALIPSO are indicated (arrows). IIR brightness temperatures dispersions around the mean value of three central pixels are represented (vertical bars). 
TABLE 4. Comparison of brightness temperature measurements obtained from CLIMAT and IIR for the three common channels in the latitude range of $43.6^{\circ}-45.2^{\circ} \mathrm{N}$, that is, in the clearest area, corresponding to the flight fs0708 of 16 May 2007 during CIRCLE-2. Position of cloud means positions of the bottom and the top of the cloud.

\begin{tabular}{|c|c|c|c|c|c|}
\hline \multicolumn{3}{|c|}{$T_{\text {CLIMAT }}-T_{\text {IIR }}(\mathrm{K})$} & \multirow{2}{*}{$\frac{\text { Channel C8 }}{1.05}$} & \multirow{2}{*}{$\frac{\text { Channel C10 }}{1.15}$} & \multirow{2}{*}{$\frac{\text { Channel Cl2 }}{0.56}$} \\
\hline Averaged measurements difference & & & & & \\
\hline Simulations in clear atmosphere & & & 0.80 & 0.04 & -0.07 \\
\hline \multirow{5}{*}{ Simulations in cloudy atmosphere } & Low cloud position $(\mathrm{km})$ & $0.5-1.0$ & 0.78 & 0.05 & -0.07 \\
\hline & & $1.5-2.0$ & 0.74 & 0.06 & -0.06 \\
\hline & Cirrus cloud position $(\mathrm{km})$ & $10.0-10.5$ & 0.74 & 0.01 & -0.08 \\
\hline & & $11.5-12.0$ & 0.78 & 0.03 & -0.07 \\
\hline & & $12.5-13.0$ & 1.15 & 0.55 & 0.68 \\
\hline
\end{tabular}

CLIMAT-AV brightness temperatures in channel C12 is shown in Fig. 11. During this leg, a cirrus deck at a top altitude of about $12 \mathrm{~km}$ was clearly identified from LNG backscattering measurements. Figure 12 shows superposed values of brightness temperatures measured by CLIMAT-AV and IIR for channels C8, C10, and C12. Because of the small deviation between the satellite's and the aircraft's tracks, an average of the three central pixels of IIR swath has again been considered. When performing latitude adjustments, a southern wind with a speed of about $20 \mathrm{~m} \mathrm{~s}^{-1}$ was taken into account.

The comparisons of brightness temperature measurements between CLIMAT-AV and IIR show strong similarities, although some differences of about $1 \mathrm{~K}$ maximum can still be noticed. Nevertheless, a similar study using computation as conducted for the Biscay '08 campaign is not easy to pursue in this case because of the lack of a large zone of clear homogeneous sky. Indeed, a quick sensitivity study under different atmospheric conditions shows that the slightest disturbing object in the upper troposphere may have an important impact on the brightness temperature values. The main results of such a study are exposed here, but are purely informational, however, because of the lack of exact knowledge about the composition of the clouds that we have to simulate. The area of $48.15^{\circ}-48.30^{\circ} \mathrm{N}$ appears to be the clearest along this leg. The input parameters for the FASDOM code follow the same protocol as that for the Biscay ' 08 campaign. To roughly take into account the radiative effect of the thin semitransparent cirrus cloud and low water clouds seen by LNG (Fig. 11) and CALIOP (Fig. 13), we assume the following estimated characteristics:

(i) Cirrus cloud optical thickness is set to $\delta \approx 0.05$ at $12-\mu \mathrm{m}$ wavelength, that is, $\delta \approx 0.1$ in the visible, as obtained from CALIOP products in this region.

(ii) To simulate a thin cirrus cloud, microphysical properties are chosen to correspond to aggregate crystals with an effective diameter of $30 \mu \mathrm{m}$ (Yang et al. 2001). (iii) Low-level water clouds optical thicknesses at $12 \mu \mathrm{m}$ is considered to be about $\delta=1$, as obtained from the integrated LNG measurements. Their optical properties are simulated assuming the standard microphysics to correspond to that of a cloud composed of spherical droplets whose effective diameter is $11 \mu \mathrm{m}$, with an effective variance of 0.13 (Stephens 1979).

An examination of the results of simulations presented in Table 4 makes it clear that the differences between CLIMAT-AV and IIR measurements do not correspond to what would be expected in a perfectly clear atmosphere. The isolated presence of each cloud layer seen under the aircraft does not allow us to explain the brightness temperature differences observed between the two instruments. The values of the brightness temperature may vary, but their difference merely remains the same. Moreover, the optical thickness of the aerosol layer slightly appearing in the backscattering LNG image, as well as its radiative effect, is negligible. The only way to come closer to the observed differences

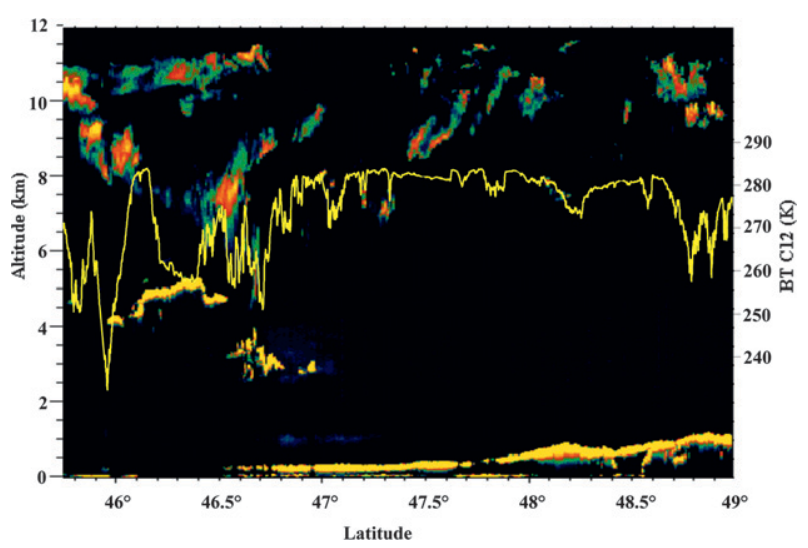

FIG. 14. Composite image obtained from LNG backscattering and CLIMAT-AV brightness temperature in channel C12 (right scale) during leg CD performed on 25 May 2007 during the CIRCLE-2 experiment, as represented in Fig. 6. 

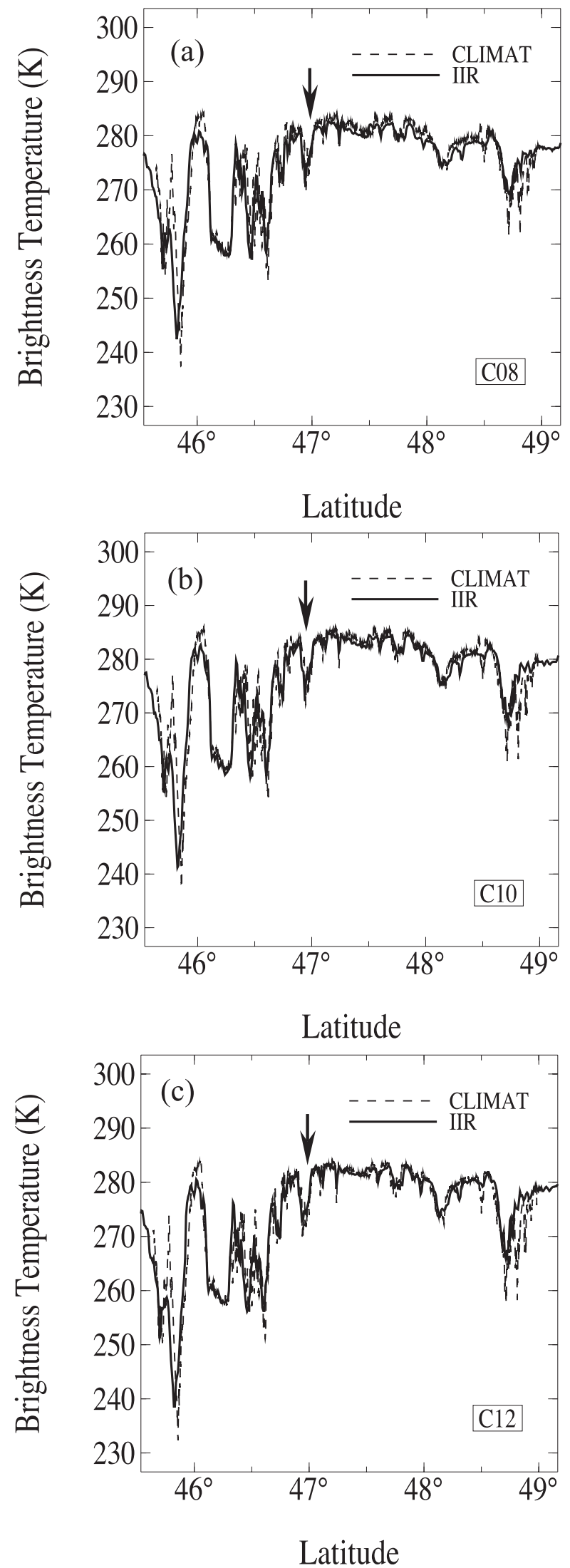

is to consider a cirrus cloud seen by IIR and not by CLIMAT-AV, as observed by CALIOP in Fig. 13. The last line of Table 4 shows that in the case of a thin cirrus cloud situated above the FF20 aircraft, the simulated differences are close to measurements and are clearly below the range of uncertainties. An explanation could also be that IIR, with its much wider resolution at the altitude of cirrus, observes clusters of clouds unnoticed by CLIMAT-AV. It is thus difficult to compare scenes where the atmospheric conditions are not homogeneous because they may not be identically seen by both radiometers, because of their difference of resolution along the track of CALIPSO, and across this track no real correction could be applied. Only situations with perfectly clear atmospheres or with large spread thick cirrus would be ideal. However, by excluding such an inhomogeneous clear area and by taking the instrumental errors into account, the measurements of both instruments turn out to be perfectly consistent.

\section{c. CIRCLE-2 case of 25 May 2007}

On 25 May 2007, the measurement track overlapped by CALIOP took place between $\mathrm{C}$ and $\mathrm{D}$ in the latitude range of $45.5^{\circ}-49.0^{\circ} \mathrm{N}$ (see Fig. 6 and Table 2). Along this track, a composite image combining LNG backscattering and brightness temperature in channel $\mathrm{C} 12$ of CLIMAT-AV is shown in Fig. 14. This figure shows a long scattered deck of cirrus in the latitude range of $45.7^{\circ}-46.8^{\circ} \mathrm{N}$ (on about a $130-\mathrm{km}$ length with a top altitude of around $11 \mathrm{~km}$ ), and the presence of low-level water clouds between the surface and 2-km altitude.

Figure 15 shows superposed values of brightness temperatures measured by CLIMAT-AV and IIR for channels $\mathrm{C} 8, \mathrm{C} 10$, and $\mathrm{C} 12$. There was no major deviation between CALIPSO and FF20 tracks during this flight; therefore, only the central pixels of the IIR swath have been considered. Additionally, following brightness temperature comparisons for both instruments, it appears that no spatial shift is necessary.

The comparison of brightness temperature shows identical behavior of the measurements of CLIMAT-AV and IIR. Some differences between the instruments can again be spotted, but no large, clear atmosphere area that is needed to perform correct simulations is observed. Only the $47.2^{\circ}-47.5^{\circ} \mathrm{N}$ latitude range shows more or less

FIG. 15. Brightness temperatures measured during the leg $\mathrm{CD}$ on 25 May 2007 during CIRCLE-2 by CLIMAT-AV and IIR in the three common channels $\mathrm{C} 8, \mathrm{C} 10$, and $\mathrm{C} 12$. The exact collocation between FF20 and CALIPSO are indicated (arrows). 
TABLE 5. Averaged brightness temperature differences between CLIMAT A-V and IIR in the three common channels for the leg CD of the flight fs0713 (25 May 2007) during the CIRCLE-2 experiment near the exact collocation. Only the latitude range $47.2^{\circ}-47.5^{\circ} \mathrm{N}$ is considered here.

\begin{tabular}{lc}
\hline \hline$T_{\text {CLIMAT }}-T_{\text {IIR }}(\mathrm{K})$ & Averaged measurements differences \\
\hline Channel C8 & 1.05 \\
Channel C10 & 0.62 \\
Channel C12 & 0.22 \\
\hline
\end{tabular}

constant values of brightness temperature. The corresponding average values along this latitude range are presented in Table 5. Simulations were carried out, but because of similarities of the atmospheric conditions between 16 and 25 May, results summed up in Table 4 are also perfectly applicable to this flight. Similar conclusions can thus be drawn because simulated brightness temperature differences are closer to measurements only in the case of a cloud unseen by one of the instruments. An accurate comparison of brightness temperatures in an atmosphere where several broken thin cirrus are present again appears fairly difficult; however, measurement differences along this leg still remain acceptable considering the instrumental absolute accuracies.

\section{Conclusions}

The accurate radiative measurements of the earthatmosphere system from satellites are essential if we want to develop radiative transfer models that include cirrus clouds. In this respect, the two airborne experiments CIRCLE- 2 and Biscay '08 constitute extremely valuable datasets for the study of cirrus clouds, but also for the validation of CALIPSO measurements. During these two campaigns, collocated airborne measurements were performed right under the track of CALIPSO using instruments very similar to those carried by the satellite. In this paper, we have compared the measurements obtained from central pixels of the infrared imager IIR on board CALIPSO with the collocated data obtained from the infrared radiometer CLIMAT-AV on board the FF20 aircraft. Direct comparisons of brightness temperature measurements allowed us to conclude that there were excellent global agreements between both instruments in the three infrared channels during these two campaigns.

However, small differences were still observed between CLIMAT-AV and IIR brightness temperature measurements. To explain these gaps, simulations were carried out using the FASDOM radiative transfer code. In the case of a perfectly clear atmosphere (as during Biscay '08) these simulations were used to precisely show that the observed gaps are inherent in the differences between the spectral channels of the two radiometers, and in the atmosphere above the FF20 aircraft that was unseen by CLIMAT-AV. On the other hand, in the case of an imperfectly clear atmosphere, that is, a scattered cirrus scene (as detected during CIRCLE-2), differences observed between the brightness temperatures are much harder to analyze using a similar scheme. Indeed, the simulations may easily become inaccurate because of our lack of precise knowledge about the state of the atmosphere, particularly about the cloud optical and microphysical properties. We have shown that the presence of even a very thin cirrus cloud only seen by one of the instruments can cause major deviance in the brightness temperature values. This fact is important because we know that the resolution of IIR pixels is much wider than the one of CLIMAT-AV, and thus such cases may be common and have to be treated carefully. Nevertheless, by taking all these considerations into account we have demonstrated that the differences between the measurements provided by IIR and CLIMAT-AV are well within the experimental uncertainties. These two airborne campaigns thus allowed us to validate IIR measurements unambiguously.

In a future paper, we will consider the cloudy cases observed during these campaigns more precisely and will use these data to retrieve cirrus optical thickness and ice crystals effective radius. The retrievals will follow an optimal estimation scheme for a good representation of uncertainties. Results will be compared with in situ measurements provided from the GF20 and with official products.

Acknowledgments. This work was funded by the Centre National d'Études Spatiales (CNES). We thank the member of Deutsches Zentrum für Luft- und Raumfahrt (DLR) and Service des Avions Français Instrumentés pour la Recherche en Environnement (SAFIRE) who organized the aircraft operations and experiment management. We would like to acknowledge ICARE center (http://www.icare.fr) in Lille, France, for the A-Train data.

\section{REFERENCES}

Ackerman, S. A., W. L. Smith, H. E. Revercomb, and J. D. Spinhirne, 1990: The 27-28 October 1986 FIRE IFO cirrus case study: Spectral properties of cirrus clouds in the $8-12 \mu \mathrm{m}$ window. Mon. Wea. Rev., 118, 2377-2388.

Anderson, T. L., and Coauthors, 2005: An "A-Train" strategy for quantifying direct climate forcing by anthropogenic aerosols. Bull. Amer. Meteor. Soc., 86, 1795-1809.

Baran, A. J., 2009: A review of the light scattering properties of cirrus. J. Quant. Spectrosc. Radiat. Transfer, 110, 1239-1260. 
and L. C.-Labonnote, 2007: A self-consistent scattering model for cirrus. I: The solar region. Quart. J. Roy. Meteor. Soc., 133, 1899-1912.

, P. Yang, and S. Havemann, 2001: Calculation of the singlescattering properties of randomly oriented hexagonal ice columns: A comparison of the $T$-matrix and the finite-difference time-domain methods. Appl. Opt., 40, 4376-4386, doi:10.1364/ AO.40.004376.

Baum, B. A., P. Yang, A. J. Heymsfield, S. Platnick, M. D. King, Y.-X. Hu, and S. T. Bedka, 2005: Bulk scattering properties for the remote sensing of ice clouds. Part II: Narrowband models. J. Appl. Meteor., 44, 1896-1911.

,,,-- C. G. Schmitt, Y. Xie, A. Bansemer, Y.-X. Hu, and Z. Zhang, 2011: Improvements in shortwave bulk scattering and absorption models for the remote sensing of ice clouds. J. Appl. Meteor. Climatol., 50, 1037-1056.

Brogniez, G., F. Parol, J.-C. Buriez, and Y. Fouquart, 1992: Bidirectional reflectances of cirrus clouds modelized from observations during the International Cirrus Experiment'98. Proceedings of the International Radiation Symposium, S. Keevallik and O. Karner, Eds., A. Deepak Publishing, 133-136.

, C. Pietras, M. Legrand, P. Dubuisson, and M. Haeffelin, 2003: A high-accuracy multiwavelength radiometer for in situ measurements in the thermal infrared. Part II: Behavior in field experiments. J. Atmos. Oceanic Technol., 20, 10231033.

- and Coauthors, 2004: Determination of cirrus radiative parameters from combination between active and passive remote sensing measurements during FRENCH/DIRAC 2001. Atmos. Res., 72, 425-452.

—, M. Legrand, B. Damiri, I. Behnert, and J.-P. Buis, 2005: Multi-channel ground based and airborne infrared radiometers. NEWRAD Proc. Ninth Int. Conf. on New Developments and Applications in Optical Radiometry, Davos, Switzerland, Physikalisch- Meteorologisches Observatorium Davos, World Radiation Center, 173-174.

Chepfer, H., G. Brogniez, L. Sauvage, P. H. Flamant, V. Trouillet, and J. Pelon, 1999: Remote sensing of cirrus radiative parameters during EUCREX'94. Case study of 17 April 1994. Part II: Microphysical models. Mon. Wea. Rev., 127, 504-518.

C.-Labonnote, L., G. Brogniez, M. Doutriaux-Boucher, J.-C. Buriez, J.-F. Gayet, and H. Chepfer, 2000: Modeling of light scattering in cirrus clouds with inhomogeneous hexagonal monocrystals: Comparison with in situ and ADEOS-POLDER measurements. Geophys. Res. Lett., 27, 113-116.

,-- J.-C. Buriez, M. Doutriaux-Boucher, J.-F. Gayet, and A. Macke, 2001: Polarized light scattering by inhomogeneous hexagonal monocrystals: Validation with ADEOS-POLDER measurements. J. Geophys. Res., 106, 12 139-12 153.

Clough, S. A., F. X. Kneizyx, and R. W. Davies, 1989: Line shape and the water vapor continuum. Atmos. Res., 23, 229-241.

Corlay, G., M.-C. Arnolfo, T. Bret-Dibat, A. Lifferman, and J. Pelon, 2000: The infrared imaging radiometer for PICASSOCENA. Tech. Rep., 14 pp. [Available online at http://smsc.cnes. fr/CALIPSO/IIR_ICSO00_S2-06.pdf.]

Delanoë, J., and R. J. Hogan, 2010: Combined CloudSat-CALIPSOMODIS retrievals of the properties of ice clouds. J. Geophys. Res., 115, D00H29, doi:10.1029/2009JD012346.

Dubuisson, P., V. Giraud, O. Chomette, H. Chepfer, and J. Pelon, 2005: Fast radiative transfer modeling for infrared imaging radiometry. J. Quant. Spectrosc. Radiat. Transfer, 95, 201220.
Garrett, T. J., and Coauthors, 2005: Evolution of a Florida cirrus anvil. J. Atmos. Sci., 62, 2352-2372.

Gayet, J.-F., and Coauthors, 1998: In situ measurements of the scattering phase function of stratocumulus, contrails and cirrus. Geophys. Res. Lett., 25, 971-974.

Giver, L. P., C. Chackerian Jr., and P. Varanasi, 2000: Visible and near infrared $\mathrm{H}_{2} \mathrm{O}$ line intensity corrections for HITRAN-96. J. Quant. Spectrosc. Radiat. Transfer, 66, 101-105.

King, M. D., S. Platnick, G. Wind, G. T. Arnold, and R. T. Dominguez, 2010: Remote sensing of radiative and microphysical properties of clouds during $\mathrm{TC}^{4}$ : Results from MAS, MASTER, MODIS, and MISR. J. Geophys. Res., 115, D00J07, doi:10.1029/ 2009JD013277.

Knapp, W. H., M. Hess, P. Stammes, R. B. A. Koelemeijer, and P. D. Watts, 1999: Cirrus optical thickness and crystal size retrieval from ATSR-2 data using phase functions of imperfect hexagonal ice crystals. J. Geophys. Res., 104, 31 721-31 730.

_ L. L. C.-Labonnote, G. Brogniez, and P. Stammes, 2005: Modeling total and polarized reflectances of ice clouds: Evaluation by means of POLDER and ATSR-2 measurements. Appl. Opt., 44, 4060-4073.

Lawson, R. P., B. A. Baker, C. G. Schmitt, and T. L. Jensen, 2001: An overview of microphysical properties of Arctic clouds observed in May and July 1998 during FIRE ACE. J. Geophys. Res., 106 (D14), 14 989-15 014.

Legrand, M., C. Pietras, G. Brogniez, and M. Haeffelin, 2000: A high-accuracy multiwavelength radiometer for in situ measurements in the thermal infrared. Part I: Characterization of the instrument. J. Atmos. Oceanic Technol., 17, 1203-1214.

Liou, K. N., 1986: Influence of cirrus clouds on weather and climate processes: A global perspective. Mon. Wea. Rev., 114, 11671199.

Mioche, G., D. Josset, J.-F. Gayet, J. Pelon, A. Garnier, A. Minikin, and A. Schwarzenboeck, 2011: Validation of the CALIPSOCALIOP extinction coefficients from in situ observations in midlatitude cirrus clouds during CIRCLE-2 experiment. J. Geophys. Res., 115, D00H25, doi:10.1029/2009JD012376.

Paltridge, G. W., and C. M. R. Platt, 1981: Aircraft measurements of solar and infrared radiation and the microphysics of cirrus cloud. Quart. J. Roy. Meteor. Soc., 107, 367-380.

Parol, F., J.-C. Buriez, G. Brogniez, and Y. Fouquart, 1991: Information content of AVHRR channels 4 and 5 with respect to the effective radius of cirrus cloud particles. J. Appl. Meteor. 30, 973-984.

Raschke, E., J. Schmetz, J. Heintzenberg, R. Kandel, and R. W. Saunders, 1990: The International Cirrus Experiment (ICE): A joint European effort. ESA J., 14, 193-199.

Rothman, L. S., K. Chance, J. Schroeder, and A. Goldman, 2001 New edition of HITRAN data base. Proc. 11th ARM Science Team Meeting, Atlanta, GA, ARM. [Available online at http:// www.arm.gov/publications/proceedings/conf11/extended_abs/ rothman_ls.pdf.]

Sauvage, L., H. Chepfer, V. Trouillet, P. H. Flamant, G. Brogniez, J. Pelon, and F. Albers, 1999: Remote sensing of cirrus radiative parameters during EUCREX'94. Case study of 17 April 1994. Part I: Observations. Mon. Wea. Rev., 127, 486503.

Stephens, G. L., 1979: Optical properties of eight water cloud types. Commonwealth Science and Industrial Research Organisation Division of Atmospheric Physics, Tech. Paper 36, 35 pp.

Takano, Y., and K. N. Liou, 1989: Solar radiative transfer in cirrus clouds. Part I: Single-scattering and optical properties of hexagonal ice crystals. J. Atmos. Sci., 46, 3-19. 
Tobin, D. C., and Coauthors, 1999: Downwelling spectral radiance observations at the SHEBA ice station: Water vapor continuum measurements from 17 to $26 \mu \mathrm{m}$. J. Geophys. Res., 104, 20812092.

Vaughan, G., C. Schiller, A. R. Mc Kenzie, K. Bower, T. Peter, H. Schlager, N. P. R. Harris, and P. T. May, 2005: SCOUTO3/ACTIVE: High-altitude aircraft measurements around deep tropical convection. Bull. Amer. Meteor. Soc., 89, 647-662.

Warren, S. G., J. Hahn, J. London, R. M. Chervin, and R. L. Jenne, 1988: Global distribution of total cloud cover and cloud type amounts over the ocean. NCAR Tech. Note TN-317 + STR.
[Available online at http://nldr.library.ucar.edu/repository/ collections/TECH-NOTE-000-000-000-467.]

WCP, 1986: A preliminary cloudless standard atmosphere for radiation computation. WCP-112, WMO/TD 24, $53 \mathrm{pp}$.

Wilber, A. C., D. P. Kratz, and S. K. Gupta, 1999: Surface emissivity maps for use in satellite retrievals of longwave radiation. Langley Research Center, NASA/TP-1000-209362, 35 pp.

Yang, P., B. C. Gao, B. A. Baum, Y. Hu, W. Wiscombe, S. C. Tsay, D. M. Winker, and S. L. Nasiri, 2001: Radiative properties of cirrus clouds in the infrared $(8-13 \mu \mathrm{m})$ spectral region. J. Quant. Spectrosc. Radiat. Transfer, 70, 473-504. 